\title{
Thermal Self-Initiation in Stable Free-Radical Polymerization of Styrene
}

\author{
By Yuejian SUN, Yaoying WU, Liguo CHEN, Zhifeng FU, and Yan SHI
}

Stable free radical polymerization (SFRP) of styrene was carried out using bis(4-bromomethylbenzoyl)peroxide (BBMBPO)/ 4-hydroxyl-2,2,6,6-tetramethyl-1-piperidinyloxy (HTEMPO) or 4,4'-azobis(4-cyanopentyl)- $\alpha$-bromoisobutyrate (ABCBIB)/ HTEMPO as bimolecular initiating system. It was found that the molecular weights of obtained polystyrenes were controlled by the concentration of HTEMPO. Besides those generated by the initiators, some polystyrene chains were formed via thermal initiation. Polystyrene chains generated by the initiator had initiating groups for atom transfer radical polymerization (ATRP) at their ends, so they grew to higher molecular weights in ATRP of styrene. While the molecular weights of polystyrene chains generated by thermal initiation kept constant in ATRP conditions because of their inert terminals for ATRP. The amount of polystyrenes generated by thermal initiation was investigated quantitatively via gel permeation chromatography technique.

KEY WORDS: Stable Free Radical Polymerization / Atom Transfer Radical Polymerization / Styrene / Thermal Self-Initiation /

In recent years, several living radical polymerization methods have attracted considerable attention from polymer chemists. Among them, stable free radical polymerization (SFRP), discovered by Georges, ${ }^{1}$ was widely used in the synthesis of block, graft, star-shaped and end functional polymers. $^{2}$

The proposed mechanism of SFRP is shown in Figure 1, where P-T is 2,2,6,6-tetramethylpiperidinyloxy (TEMPO) capped dormant polymer, $\mathrm{P}^{\bullet}$ is growing polymer radical and $\mathrm{T}^{\bullet}$ is stable nitroxide radical. The capping reaction is reversible, where $k_{\mathrm{c}}$ and $k_{\mathrm{d}}$ are the rate constants for capping and release of the growing polymer chain, respectively. Furthermore, $k_{\mathrm{c}}$ is sufficiently larger than $k_{\mathrm{d}}$, which controls the concentration of the growing polymer radical in the system at a very low level. Therefore the bimolecular termination is nearly suppressed and living polymerization is achieved.

Initiating systems for SFRP can be divided into two classes: bimolecular system and unimolecular system. In unimolecular system, alkylated TEMPO derivatives are used as initiators which dissociate to provide both the initiating radical and the stable radical. While in bimolecular system, a traditional free radical initiator, such as benzoyl peroxide (BPO) or 2,2'azobisisobutyronitrile (AIBN), is used in conjunction with TEMPO. Hawker and his co-workers ${ }^{3}$ have compared the two initiating systems and found that polymers prepared in unimolecular system had narrower molecular weight distributions.

SFRP of styrene was usually carried out at high temperature. Therefore thermal self-initiation could not be avoided. ${ }^{4,5}$ Matyjaszewski, ${ }^{6,7}$ Fukuda $^{8}$ and Yang $^{9}$ studied unimolecular initiating systems and concluded that polymerization rate of SFRP was mainly controlled by thermal self-initiation. However, according to their simulation results, only a few percent of the total number of polymer chains were generated by

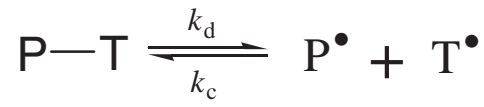

Figure 1. Mechanism of SFRP.

thermal self-initiation. Yoshida and his coworkers ${ }^{10-12}$ also investigated bimolecular systems and found that the concentration of growing polymer chain was equal to the initial concentration of stable nitroxide radical, even when the concentration of stable nitroxide radical was very high. This shows that the ratio of polymer chains formed by thermal selfinitiation might be significant.

In this article, we reported a novel strategy for quantitative investigation of thermal self-initiation in bimolecular initiating system of SFRP. We synthesized two free radical initiators, bis(4-bromomethylbenzoyl)peroxide (BBMBPO) and 4,4' -azobis(4-cyanopentyl)- $\alpha$-bromoisobutyrate (ABCBIB), which were both conventional kind of radical initiators functionalized with initiating groups for atom transfer radical polymerization (ATRP). SFRP of styrene was carried out using these two initiators along with HTEMPO. Due to the thermal selfinitiation of styrene, some polystyrene chains were generated by the initiators, and the other polystyrene chains were thermally initiated. Polystyrene chains generated by the initiators had initiating groups for ATRP at their ends, so they could grow via ATRP mechanism. While polystyrene chains generated by thermal self-initiation did not have initiating groups for ATRP at their ends, so their molecular weights would keep constant in ATRP conditions. Base on the GPC traces, we could calculate the ratio of polystyrene chains generated by thermal self-initiation. To our knowledge, it is the first time to use GPC technique to investigate thermal selfinitiation in SFRP of styrene. 


\section{EXPERIMENTAL}

\section{Materials}

Styrene (99\%, Beijing Yanshan Petrochemical Co.) was dried over anhydrous magnesium sulfate and distilled under reduced pressure before use. 4-Hydroxyl-2,2,6,6-tetramethyl-1piperidinyloxy (HTEMPO) (99\%, Beijing Huashang Reagent Plant) was recrystallized from hexane and dried under vacuum at room temperature. Cuprous bromide $(\mathrm{CuBr})$ was purified by being stirred in acetic acid, washed with acetone and then dried in vacuum. $N, N, N^{\prime}, N^{\prime}, N^{\prime \prime}$-Pentamethyldiethylene-triamine (PMDETA) (99\%, Aldrich) and all other reagents were used without any further purification.

BBMBPO was synthesized as follows: ${ }^{15}$ firstly, $20.4 \mathrm{~g}$ ( $150 \mathrm{mmol})$ of $p$-methyl benzoic acid and $53.6 \mathrm{~g}(450 \mathrm{mmol})$ of thionyl chloride were added to a three-necked roundbottomed flask equipped with a magnetic stirring bar. The reaction mixture was heated at refluxing temperature for $8 \mathrm{~h}$. p-Methyl benzoyl chloride was obtained by distillation under reduced pressure in $85 \%$ yield. Secondly, $9.8 \mathrm{~g}$ $(63.5 \mathrm{mmol})$ of $p$-methyl benzoyl chloride were converted to $p$-bromomethyl benzoly chloride by being treated with $0.91 \mathrm{~g}(5.5 \mathrm{mmol})$ of azobisisobutyronitrile and $11.3 \mathrm{~g}(63.5$ mmol) of $\mathrm{N}$-bromosuccinimide in $75 \mathrm{~mL}$ of $\mathrm{CCl}_{4}$ in a threenecked round-bottomed flask at refluxing temperature for $8 \mathrm{~h}$. Pure $p$-bromomethyl benzoly chloride was obtained by recrystallization from chloroform in $55 \%$ yield. Finally, $1.95 \mathrm{~g}(7.0 \mathrm{mmol})$ of $p$-bromomethyl benzoly chloride in $15 \mathrm{~mL}$ of diethyl ether were added dropwise to aqueous solution of $0.55 \mathrm{~g}(7.0 \mathrm{mmol})$ of sodium peroxide under stirring at $0{ }^{\circ} \mathrm{C}$. After filtration, the crude product was dried under vacuum. BBMBPO was recrystallized from chloroform as a white solid in $53 \%$ yield. ${ }^{1} \mathrm{H} \mathrm{NMR}(600 \mathrm{MHz}$, $\mathrm{CDCl}_{3}$ ), $\delta$ (TMS, ppm): 7.5, 8.0 (each s, 8H, $\mathrm{ArH}$ ), 4.5 (s, 4H, $\mathrm{CH}_{2} \mathrm{Br}$ ).

ABCBIB was synthesized as follows: $7.56 \mathrm{~g}(30.0 \mathrm{mmol})$ of 4,4'-azobis(4-cyano-1-pentanol) and $5.93 \mathrm{~g}(75.0 \mathrm{mmol})$ of pyridine were dissolved in $10 \mathrm{~mL}$ of anhydrous chloroform in a three-necked round-bottomed flask. $17.25 \mathrm{~g}(75.0 \mathrm{mmol})$ of $\alpha$ bromoisobutyryl bromide in $30 \mathrm{~mL}$ of anhydrous chloroform were added dropwise. After being stirred at $0{ }^{\circ} \mathrm{C}$ for $6 \mathrm{~h}$, the reaction mixture was stirred at room temperature for $12 \mathrm{~h}$. The pyridinium salt was removed by filtration. The mixture was first washed with aqueous sodium hydrogen carbonate $(5 \mathrm{wt} \%$, $3 \times 150 \mathrm{~mL})$ and then washed with distilled water $(3 \times 150$ $\mathrm{mL}$ ) until $\mathrm{pH}$ value of the solution reached 7.0. The organic phase was dried with anhydrous magnesium sulfate overnight. After magnesium sulfate was filtered off, the solvent was removed by rotary evaporation. The crude product was dissolved in a mixture of chloroform and ethyl acetate $(4 / 5$, volume ratio) and passed through a silica gel column prepared with the same solvents. The first fraction was collected. The solvent was removed by rotary evaporation and ABCBIB was obtained as light yellow oil in $46 \%$ yield. ${ }^{1} \mathrm{H}$ NMR $(600 \mathrm{MHz}$, $\mathrm{CDCl}_{3}$ ), $\delta$ (TMS, ppm): 2.26, 2.15, 1.88 and 1.72 (each m, 8H,
$\left.\mathrm{CH}_{2}\right), 1.92$ [s, 12H, $\left.\left(\mathrm{CH}_{3}\right)_{2} \mathrm{CBrCOO}\right], 4.23\left(\mathrm{~m}, 4 \mathrm{H}, \mathrm{CH}_{2} \mathrm{O}\right)$, 1.68 (s, 6H, $\mathrm{CH}_{3} \mathrm{CCN}$ ).

\section{SFRP of Styrene}

In a typical experiment, $20 \mathrm{~g}(192.3 \mathrm{mmol})$ of styrene, $0.856 \mathrm{~g}(2.0 \mathrm{mmol})$ of BBMBPO and $0.314 \mathrm{~g}(2.0 \mathrm{mmol})$ of HTEMPO were added to a $100 \mathrm{~mL}$ dried round-bottomed flask equipped with a magnetic stirrer. After the flask was sealed with a rubber septum, it was degassed by five freeze-pumpthaw cycles and subsequently purged under argon atmosphere, immersed in an oil bath thermostated at $95^{\circ} \mathrm{C}$ for $3.5 \mathrm{~h}$, and then the temperature was quickly increased to $125^{\circ} \mathrm{C}$. At definite time intervals, about $1 \mathrm{~mL}$ of the sample was withdrawn from the flask using argon-filled gas-tight syringes to determine molecular weights and monomer conversions. Polystyrene was obtained by precipitation in a large amount of cold methanol, dried under vacuum at room temperature and stored at $-15^{\circ} \mathrm{C}$ until further use.

\section{ATRP of Styrene in the Presence of Polystyrene Prepared Above}

In a typical experiment, a solution containing $0.3 \mathrm{mmol}$ of polystyrene prepared above, $15 \mathrm{~g}$ of styrene, $0.043 \mathrm{~g}(0.3 \mathrm{mmol})$ of $\mathrm{CuBr}$ and $0.052 \mathrm{~g}(0.3 \mathrm{mmol})$ of PMDETA were added to a $100 \mathrm{~mL}$ dried round-bottomed flask equipped with a magnetic stirrer. After the flask was sealed with a rubber septum, it was degassed by five freeze-pump-thaw cycles and subsequently purged under argon atmosphere, and immersed in an oil bath thermostated at $80^{\circ} \mathrm{C}$. At definite time intervals, about $1 \mathrm{~mL}$ of the sample were withdrawn from the flask using argon-filled gas-tight syringes to determine molecular weights and monomer conversions. The sample was precipitated with cold methanol and dried under vacuum at room temperature.

\section{Characterization}

Monomer conversions were determined gravimetrically. The number-average molecular weights and molecular weight distributions were measured by gel permeation chromatography (GPC) on a system equipped with a Waters 515 pump, three columns (Styragel HR1, HT3, and HT4) and a Water 2410 refractive index detector with $\mathrm{THF}\left(40^{\circ} \mathrm{C}\right)$ as the eluant at a flow rate of $1 \mathrm{~mL} / \mathrm{min}$, or Tosoh HPLC 8220 chromatography (column, TSK-Gel Super HZM-M $\times 2$ ) with THF $\left(40^{\circ} \mathrm{C}\right)$ as the eluent at a flow rate of $0.35 \mathrm{~mL} / \mathrm{min}$. Polystyrene standards were used to generate the calibration curve. ${ }^{1} \mathrm{H}$ NMR spectra were recorded on a Bruker AV 600-MHz spectrometer with $\mathrm{CDCl}_{3}$ as solvent at room temperature.

\section{RESULTS AND DISCUSSION}

\section{SFRP of Styrene Using BBMBPO as Initiator}

Bulk radical polymerization of styrene was carried out in the presence of HTEMPO with BBMBPO as an initiator. Although the half-time of BBMBPO was not determined, the same reaction condition as that for general SFRP when BPO was used. Firstly, the reaction mixture was heated at $95^{\circ} \mathrm{C}$ for $3.5 \mathrm{~h}$. 


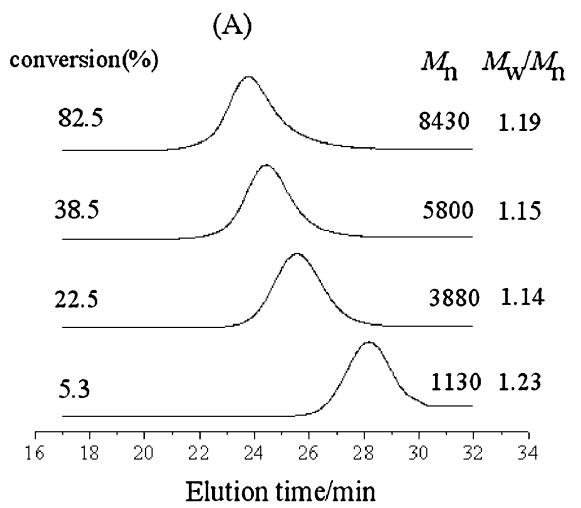

(B)

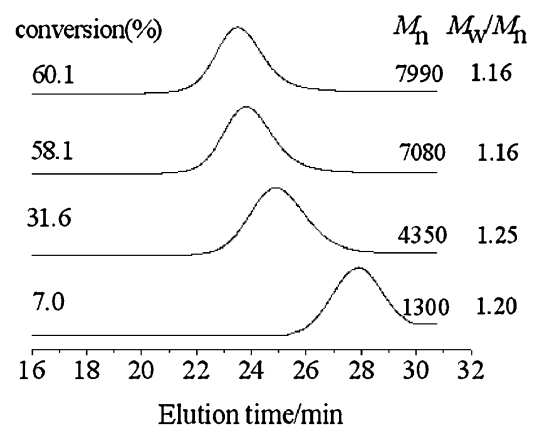

(C)

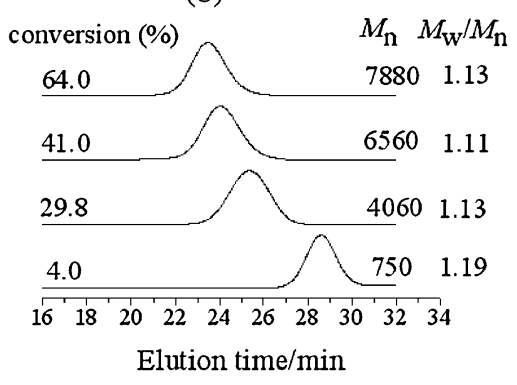

Figure 2. GPC curves of polystyrenes obtained via SFRP at different monomer conversions. Conditions: (A) [BBMBPO]:[HTEMPO] = 1:1; BBMBPO $0.856 \mathrm{~g}(2 \mathrm{mmol})$, HTEMPO $0.314 \mathrm{~g}(2 \mathrm{mmol}), \mathrm{St}$, $20 \mathrm{~g}$ (B) [BBMBPO]:[HTEMPO] $=1: 2 ;$ BBMBPO $0.428 \mathrm{~g}(1 \mathrm{mmol})$, HTEMPO $0.314 \mathrm{~g}(2 \mathrm{mmol})$, St, $20 \mathrm{~g}(\mathrm{C})$ [BBMBPO]:[HTEMPO] = $1: 3$, BBMBPO $0.428 \mathrm{~g}(1 \mathrm{mmol})$, HTEMPO $0.516 \mathrm{~g}(3 \mathrm{mmol}), \mathrm{St}$, $30 \mathrm{~g}$.

After nearly all the BBMBPO was consumed, the temperature was increased to $125^{\circ} \mathrm{C}$. At this temperature, the C-ON bond of the alkoxyamine formed at $95^{\circ} \mathrm{C}$ underwent a reversible homolytic cleavage, producing a stable nitroxide radical and a propagating active radical, which could add to monomer before being capped again by the stable nitroxide radical. This thermally reversible capping reaction reduced the concentration of propagating radical chain in the polymerization mixture, and bimolecular termination reaction could be neglected.

The molar ratio of HTEMPO to BBMBPO varied from 1.0 to 3.0. The number-average molecular weights $\left(M_{\mathrm{n}}\right)$ and polydispersity indexes $\left(M_{\mathrm{w}} / M_{\mathrm{n}}\right)$ of the obtained polymers are shown in Figure 2. It could be found that the peak of GPC trace shifted to higher molecular weight direction with the increase of monomer conversion and that all the obtained polymers

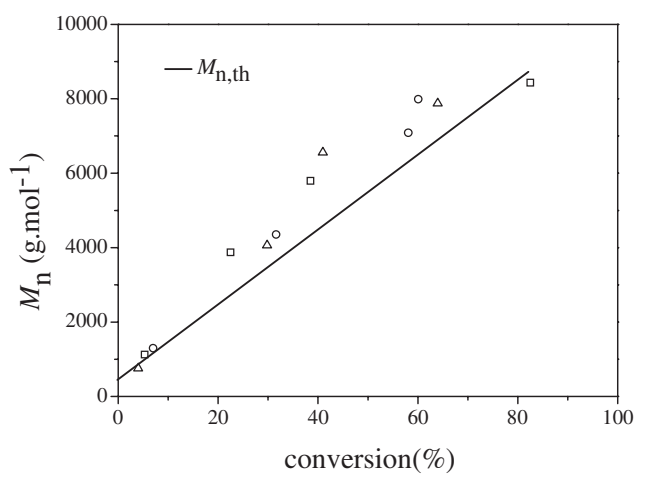

Figure 3. Conversion dependence of number-average molecular weights of polystyrenes initiated by BBMBPO in the presence of HTEMPO. Conditions: $(\square)$ [BBMBPO]:[HTEMPO] = 1:1; $(\bigcirc)$ [BBMBPO]: $[$ HTEMPO] $=1: 2 ;(\triangle)$ [BBMBPO]:[HTEMPO $=1: 3$. For other conditions, see Figure 2.

showed unimodal GPC curves. The polydispersity indexes maintained below 1.25 throughout the conversion region studied.

As shown in Figure 3, the molecular weight increased with the monomer conversion, indicating that the polymerization proceeded in accordance with a living polymerization mechanism. Furthermore, the molecular weight increased in an approximately linear fashion with the monomer conversion, and agreed well with the theoretical number-average molecular weight calculated by eq 1 .

$$
M_{\mathrm{n}, \mathrm{th}}=\frac{[\mathrm{M}]_{0}}{[\mathrm{~T}]_{0}} \times M_{\mathrm{St}} \times X+214+172
$$

where $[\mathrm{M}]_{0}$ is the initial concentration of monomer, $[\mathrm{T}]_{0}$ is the initial concentration of HTEMPO in the polymerization system, $X$ is the monomer conversion, $M_{\mathrm{St}}$ is the molecular weight of styrene, and 214 and 172 are the molecular weight of BBMBPO moiety and HTEMPO respectively.

The above results show that the molecular weights of polystyrenes were controlled by the concentration of HTEMPO, rather than that of BBMBPO. This agrees well with the conclusion obtained by Yoshida. ${ }^{10-12}$

The structure of polystyrene sample was studied by ${ }^{1} \mathrm{H}$ NMR. A typical ${ }^{1} \mathrm{H}$ NMR spectrum of the polystyrene (PSt-1, $M_{\mathrm{n}}=3400, M_{\mathrm{w}} / M_{\mathrm{n}}=1.14$, determined by GPC) is shown in Figure 4. The polystyrene sample was prepared by SFRP where the ratio of BBMBPO to HTEMPO was 1 . The signal at $4.46 \mathrm{ppm}$ was the characteristic peak of the methylene protons of $-\mathrm{CH}_{2} \mathrm{Br}$, and aromatic protons of styrene units were corresponded to signals at $6.2-7.3 \mathrm{ppm}$. The signals at 7.38 and $7.81 \mathrm{ppm}$ were assigned to the aromatic protons at ortho and meta position of the benzoyl moiety attached to the polymer head group. The characteristic peaks of the methylene protons bonded to the BBMBPO moiety, methine proton coupled to HTEMPO and another methine proton originated from HTEMPO were from 3.8 to $4.3 \mathrm{ppm}$. According to the peak intensity ratio of peak (a) and peak (d), the number-average molecular weight of polystyrene was calculated to be 7000 . Comparing this value with that obtained by GPC, it could be 

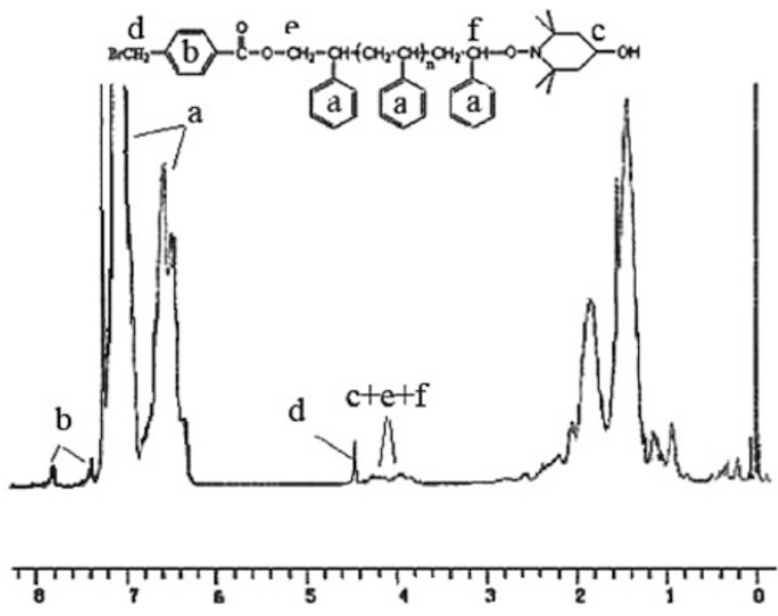

Figure 4. ${ }^{1} \mathrm{H}$ NMR spectrum of PSt- $1\left(M_{\mathrm{n}}=3400, M_{\mathrm{w}} / M_{\mathrm{n}}=1.14\right.$, determined by GPC).

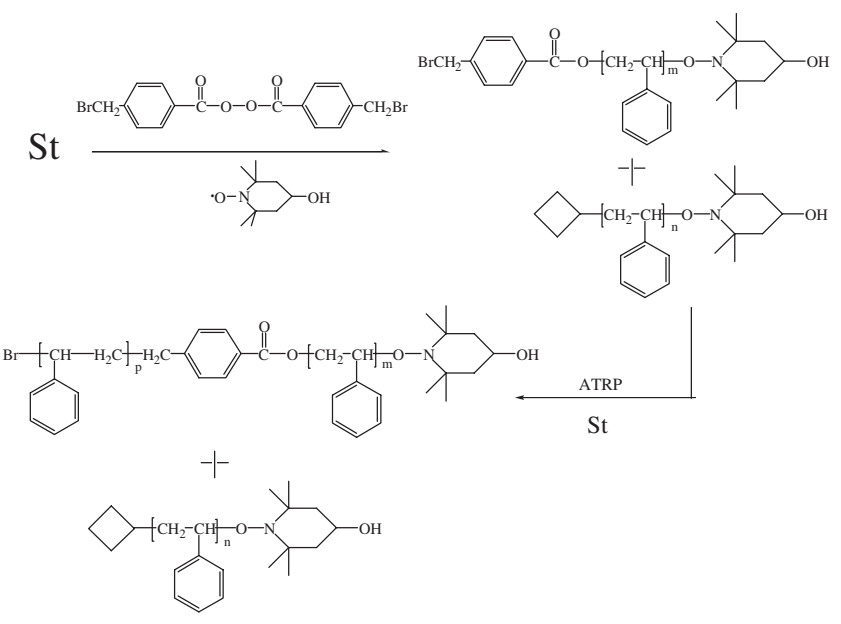

$\widehat{~: ~ i s ~ t h e ~ g r o u p ~ g e n e r a t e d ~ b y ~ t h e r m a l ~ i n i t i a t i o n ~}$

Figure 5. Experiment route of styrene polymerization.

concluded that the ratio of polymer chains initiated by thermal initiation was about $50 \%$.

\section{Quantitative Determination of Thermal Initiation in the SFRP of Styrene via GPC Technique}

As shown in Figure 5, polystyrene chains formed by the decomposition of BBMBPO should have bromide atoms at the $\alpha$-ends. These bromide atoms were efficient initiator for ATRP of styrene. While polystyrene chains generated by thermal initiation were inert for ATRP. Therefore, if polystyrenes prepared by SFRP were used as macroinitiator for ATRP of styrene, some polystyrene chains would grow to higher molecular weights, but the $M_{\mathrm{n}}$ of the other part of polystyrene chains will keep constant. Therefore, the molecular weight distributions of polystyrenes obtained from ATRP of styrene initiated by polystyrenes from SFRP of styrene would be
Table I. Polystyrene samples prepared by SFRP (BBMBPO/HTEMPO system) $^{\mathrm{a}}$

\begin{tabular}{lccccccc}
\hline & $\begin{array}{c}\text { BBMBPO } \\
(\mathrm{mmol})\end{array}$ & $\begin{array}{c}\text { HTEMPO } \\
(\mathrm{mmol})\end{array}$ & St $(\mathrm{g})$ & $\mathrm{t}(\mathrm{h})$ & Conversion $^{\mathrm{b}}(\%)$ & $M_{\mathrm{w}} / M_{\mathrm{n}}$ & $M_{\mathrm{n}}{ }^{\mathrm{c}}$ \\
\hline PSt-1 & 1.00 & 1.0 & 10 & 4.5 & 28.3 & 1.14 & 3400 \\
PSt-2 & 0.50 & 1.0 & 10 & 16 & 24.9 & 1.16 & 4500 \\
PSt-3 & 0.67 & 2.0 & 20 & 16 & 21.3 & 1.13 & 3500 \\
\hline
\end{tabular}

${ }^{a}$ For polymerization conditions, see Figure 2. ${ }^{b}$ Determined gravimetrically. ' Determined by GPC equipped with Water 515 pump, see characterization part.

bimodal. Using GPC software kindly supplied by Beijing Longzhida Co., we could calculate the molecular weights of the two peaks respectively. The amount of polystyrene chains having benzyl bromide end groups $\left(\mathrm{N}_{\mathrm{Br}}\right)$ could be calculated according to eq 2 .

$$
\mathrm{N}_{\mathrm{Br}}=X \times \mathrm{m} /\left(M_{\mathrm{n} 1}-M_{\mathrm{n} 2}\right)
$$

where $X$ is monomer conversion, $\mathrm{m}$ is the initial mass of styrene $(15 \mathrm{~g}), M_{\mathrm{n} 1}$ and $M_{\mathrm{n} 2}$ are number-average molecular weights corresponding to the two peaks calculated by GPC software.

Three polystyrene samples prepared via SFRP were used. Table I shows their preparation formulations, number-average molecular weights and polydispersity indexes determined by GPC.

ATRP of styrene was carried out at $80^{\circ} \mathrm{C}$ in the presence of polystyrene prepared by SFRP with $\mathrm{CuBr} / \mathrm{PMEDTA}$ complex as the catalyst system. It should be pointed out that at this temperature $\mathrm{C}$-ON bond at the $\omega$-end of polystyrene chain could not undergo a reversible homolytic cleavage and produce a propagating active polymer radical. ${ }^{13}$ Therefore, only polystyrene chains formed by the decomposition of BBMBPO could grow via ATRP to higher molecular weights, while the molecular weights of those formed by thermal initiation would keep constant.

Figure 6 shows the GPC traces of the products obtained at different monomer conversions. It can be seen that there are two peaks, even at higher conversions. This indicates that there were indeed some polystyrene chains did not have initiator moiety at their $\alpha$-ends.

The amount of polystyrene chains having benzyl bromide end groups was calculated according to eq 2 and the data in Figure 6. The results are listed in Table II. From Table II, we find that all the three polystyrene samples contained a large amount of polymer chains which could not initiate ATRP of styrene. That is to say, all the three polystyrene samples contained the polymer chains initiated by thermal initiation of styrene. Furthermore, the ratio of polymer chains initiated by thermal initiation increased from PSt-1 to PSt-3, indicating that the ratio of polymer chains formed by thermal initiation increased with the increase of the ratio of HTEMPO to BBMBPO.

\section{SFRP of Styrene Using ABCBIB as Initiator}

In order to further prove that thermal initiation indeed plays 

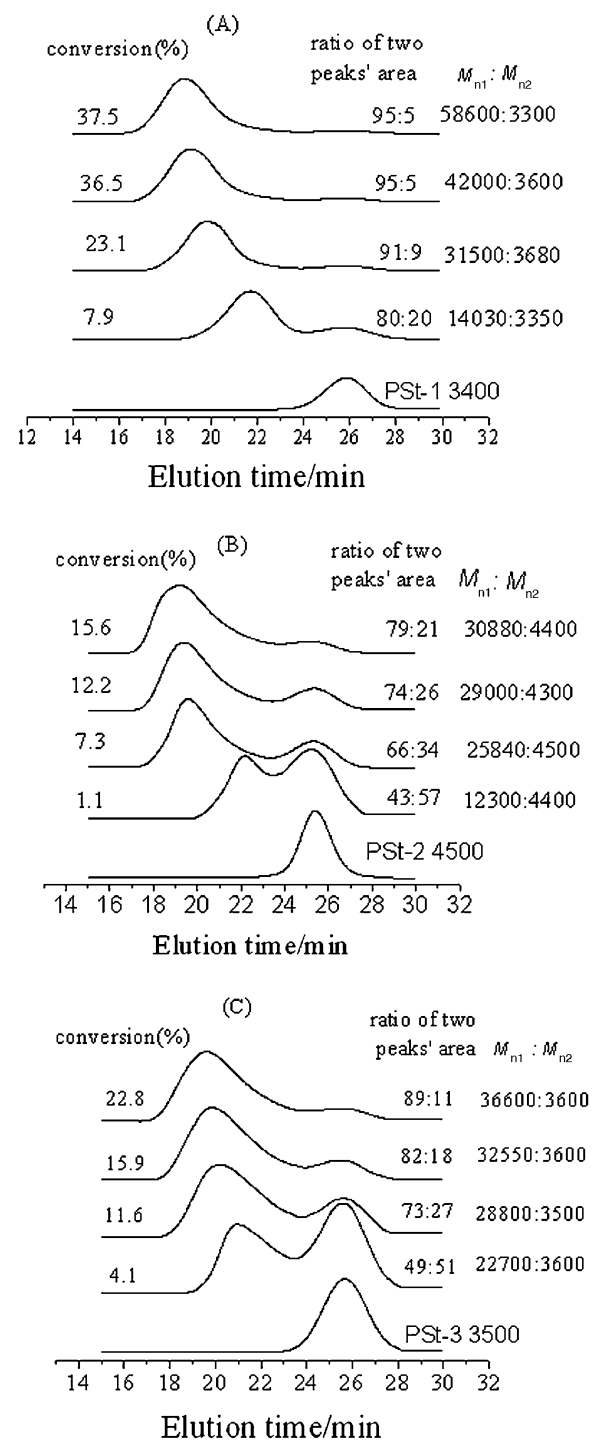

Figure 6. GPC traces of polystyrenes obtained via ATRP at different monomer conversions. (A) PSt-1 (B) PSt-2 (C) PSt-3 Conditions: PSt $0.3 \mathrm{mmol}$, CuBr $0.3 \mathrm{mmol}$, PMDETA $0.3 \mathrm{mmol}$, St $15 \mathrm{~g}, 80^{\circ} \mathrm{C}$.

an important role in SFRP of bimolecular initiation system, we used another initiator, ABCBIB, in SFRP of styrene. The molar ratios of $\mathrm{HTEMPO}$ to $\mathrm{ABCBIB}$ were $3: 1$ and 4:1 respectively. As shown in Figure 7, the peaks of GPC trace shifted to higher molecular weight direction with the increase of monomer conversion and all the obtained polymers showed unimodal GPC curves. The polydispersity indexes maintained below 1.12 throughout the conversion regions studied. And the numberaverage molecular weights $\left(M_{\mathrm{n}}\right)$ of polystyrenes determined by GPC agreed with the theoretical ones. These results are similar with those obtained by the BBMBPO/HTEMPO system.

As shown in Figure 8, polystyrene chains generated by the decomposition of ABCBIB had 2-bromoisobutyryloxy group at the $\alpha$-ends. It is well known that ethyl 2-bromoisobutyrate is an excellent initiator for ATRP of styrene with high initiating efficiency. ${ }^{14}$ Therefore, the polystyrene chains generated by the decomposition of ABCBIB could be used as macroinitiator
Table II. Composition of polystyrenes prepared by SFRP (BBMBPO/HTEMPO system) $^{\mathrm{a}}$

\begin{tabular}{ccccc}
\hline & $\mathrm{N}_{\mathrm{Br}}(\mathrm{mmol})^{\mathrm{b}}$ & $\mathrm{N}_{\text {total }}(\mathrm{mmol})^{\mathrm{c}}$ & $\mathrm{N}_{\text {th }}(\mathrm{mmol})^{\mathrm{d}}$ & $\mathrm{N}_{\text {th }} / \mathrm{N}_{\text {total }}$ \\
\hline PSt-1 & 0.120 & 0.300 & 0.180 & 0.60 \\
PSt-2 & 0.075 & 0.300 & 0.225 & 0.75 \\
PSt-3 & 0.070 & 0.300 & 0.230 & 0.77 \\
\hline
\end{tabular}

aData calculated from Figure $6 .{ }^{b} \mathrm{~N}_{\mathrm{Br}}$ is the average molar quantity of the polymer chains having benzyl bromide end groups. ${ }^{\mathrm{C}} \mathrm{N}_{\text {total }}$ is the molar quantity of PSt (prepared by SFRP) added. ${ }^{d} \mathrm{~N}_{\text {th }}$ is the molar quantity of polymer chains generated by thermal initiation.

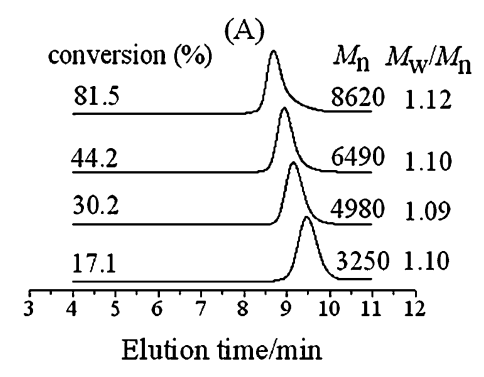

(B)

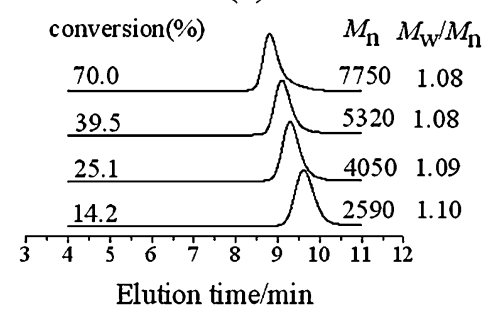

Figure 7. GPC curves of polystyrene obtained via SFRP at different monomer conversions. Conditions: HTEMPO $0.344 \mathrm{~g}(2 \mathrm{mmol})$, $\mathrm{St} 20 \mathrm{~g}, 85^{\circ} \mathrm{C}$ for $3.5 \mathrm{~h}$ and the temperature was then increased to $125^{\circ} \mathrm{C}$. (A) $[\mathrm{ABCBIB}]:[\mathrm{HTEMPO}]=1: 3 ; A B C B I B \quad 0.367 \mathrm{~g}(0.67$ $\mathrm{mmol}),(B)[\mathrm{ABCBIB}]:[\mathrm{HTEMPO}]=1: 4, \quad A B C B \mid B \quad 0.275 \mathrm{~g} \quad(0.5$ $\mathrm{mmol})$.

for ATRP of styrene. While polystyrene chains generated by thermal initiation were inert for ATRP.

ATRP of styrene using polystyrenes obtained via SFRP with ABCBIB as initiator in the presence of HTEMPO was carried out. Two polystyrene samples listed in Table III were used. The GPC traces of the products obtained at different monomer conversions are shown in Figure 9.

The amount of polystyrenes with 2-bromoisobutyrate at the $\alpha$-end was also calculated according to the eq 2 and the data in Figure 9. The results are shown in Table IV. From Table IV, it could be found that the results were similar with that of BBMBPO/HTEMPO system. The ratio of polystyrene chains generated by thermal initiation increased from PSt-4 to PSt-5, indicating the ratio of polymer chains formed by thermal initiation increased with the increase of the ratio of HTEMPO to $\mathrm{ABCBIB}$.

In addition, SFRP of styrene with the molar ratio of HTEMPO to ABCBIB to be $1: 1$ was also carried out. From the GPC results we found that thermal initiation of styrene could not be observed. We believed that it was due to the higher initiating efficiency of ABCBIB than that of BBMBPO. 


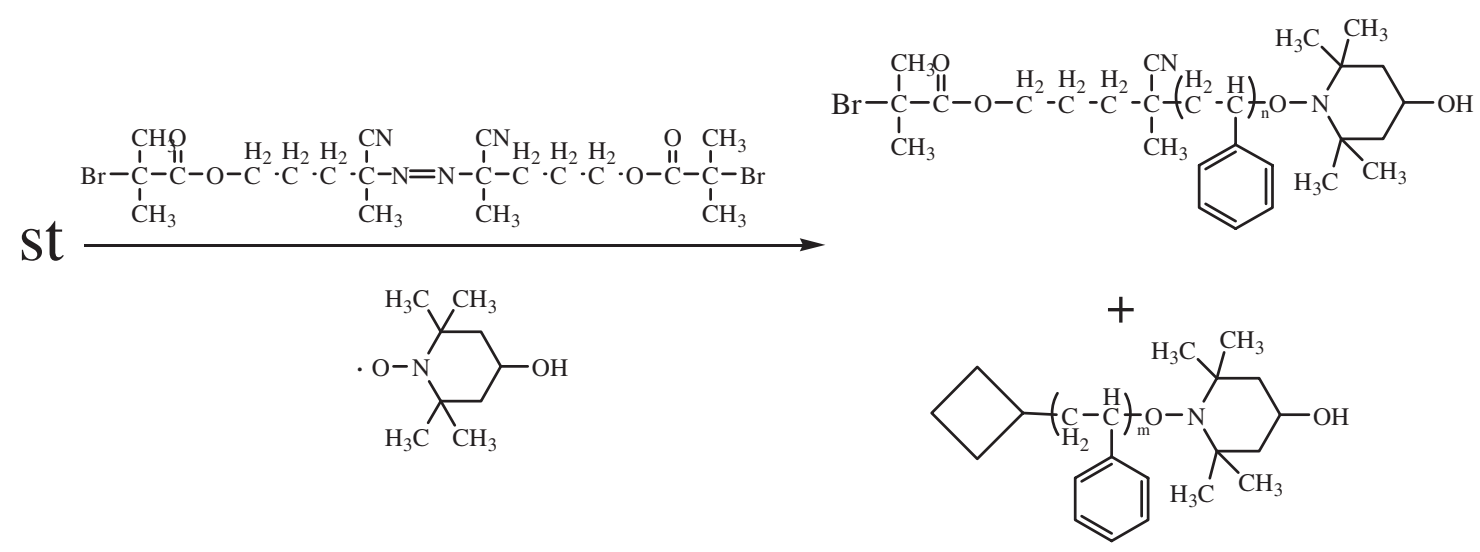

Figure 8. Experiment route of SFRP of styrene initiated by ABCBIB.

Table III. Polystyrene samples prepared by SFRP (ABCBIB/HTEMPO system) $^{\mathrm{a}}$

\begin{tabular}{cccccccc}
\hline & $\begin{array}{c}\text { ABCBIB } \\
(\mathrm{mmol})\end{array}$ & $\begin{array}{c}\text { HTEMPO } \\
(\mathrm{mmol})\end{array}$ & St $(\mathrm{g})$ & $\mathrm{t}(\mathrm{h})$ & Conversion $^{\mathrm{b}}(\%)$ & $M_{\mathrm{w}} / M_{\mathrm{n}}{ }^{\mathrm{b}}$ & $M_{\mathrm{n}}{ }^{\mathrm{c}}$ \\
\hline PSt-4 & 0.67 & 2.0 & 20 & 17.0 & 29.5 & 1.09 & 4790 \\
PSt-5 & 0.50 & 2.0 & 20 & 21.0 & 41.2 & 1.12 & 6320 \\
\hline
\end{tabular}

${ }^{a}$ For polymerization conditions, see Figure 7. ${ }^{b}$ Determined gravimetrically. 'Determined by Tosoh HPLC 8220 chromatography, see characterization part.
Table IV. Composition of polystyrene prepared by SFRP (ABCBIB/HTEMPO system) ${ }^{\mathrm{a}}$

\begin{tabular}{ccccc}
\hline & $\mathrm{N}_{\mathrm{Br}}(\mathrm{mmol})^{\mathrm{b}}$ & $\mathrm{N}_{\text {total }}(\mathrm{mmol})^{\mathrm{c}}$ & $\mathrm{N}_{\text {th }}(\mathrm{mmol})^{\mathrm{d}}$ & $\mathrm{N}_{\text {th }} / \mathrm{N}_{\text {total }}$ \\
\hline PSt-4 & 0.138 & 0.200 & 0.062 & 0.31 \\
PSt-5 & 0.130 & 0.200 & 0.070 & 0.35 \\
\hline
\end{tabular}

aData calculated from Figure 9. ${ }^{b} \mathrm{~N}_{\mathrm{Br}}$ is the average molar quantity of the polymer chains having benzyl bromide end groups. ${ }^{\mathrm{C}} \mathrm{N}_{\text {total }}$ is the molar quantity of PSt (prepared by SFRP) added. ${ }^{d} N_{t h}$ is the molar quantity of polymer chains generated by thermal initiation.

As for the thermal initiation in unimolecular initiation system of styrene, we will report the results in the future.

\section{CONCLUSIONS}

In SFRP of styrene initiated by biomolecular systems, BBMBPO/HTEMPO and ABCBIB/HTEMPO, the numberaverage molecular weight was controlled by HTEMPO, not by BBMBPO or ABCBIB.

Some polystyrene chains obtained by the above bimolecular initiating systems had initiating groups for ATRP at their $\alpha$ ends, which could grow to higher molecular weights. While the other generated by thermal initiation were inert at ATRP conditions, so their molecular weights kept constant. Furthermore, the higher the ratio of HTEMPO to BBMBPO or ABCBIB was, the more the polystyrene chains would be generated by thermal initiation.

Acknowledgment. We thank the Beijing Municipal Commission of Education for its financial support.

Received: October 22, 2008

Accepted: July 3, 2009

Published: August 26, 2009

\section{REFERENCES}

1. M. K. Georges, R. P. N. Veregin, P. M. Kazmaier, and G. K. Hamer, Macromolecules, 26, 2987 (1993).

2. C. J. Hawker, A. W. Bosman, and E. Harth, Chem. Rev., 101, 3661 
(2001).

3. C. J. Hawker, G. B. George, and A. Orellana, Macromolecules, 29 , 5245 (1996).

4. W. Devonport, L. Michalak, E. Malmström, M. Mate, B. Kurdi, and C. J. Hawker, Macromolecules, 30, 1929 (1997).

5. D. B. Boutevin, Eur. Polym. J., 35, 815 (1999).

6. D. Greszta and K. Matyjaszewski, Macromolecules, 29, 7661 (1996).

7. D. Greszta and K. Matyjaszewski, Macromolecules, 29, 5239 (1996).

8. T. Fukuda and T. Terauchi, Macromolecules, 29, 6393 (1996).

9. J. P. He, H. D. Zhang, J. M. Chen, and Y. L. Yang, Macromolecules,
30, 8010 (1997).

10. E. Yoshida, J. Polym. Sci., Part A: Polym. Chem., 34, 2937 (1996).

11. E. Yoshida and T. Fuji, J. Polym. Sci., Part A: Polym. Chem., 35, 2371 (1997).

12. E. Yoshida and T. Fuji, J. Polym. Sci., Part A: Polym. Chem., 36, 269 (1998).

13. Y. Shi, Z. F. Fu, B. Y. Li, and W. T. Yang, J. Polym. Sci., Part A: Polym. Chem., 44, 2468 (2006).

14. K. Matyjaszewski and J. H. Xia, Chem. Rev., 101, 2921 (2001).

15. B. Hazer, Eur. Polym. J., 26, 1167 (1990). 